\title{
Use of the 95-degree angled blade plate with biological and mechanical augmentation to treat proximal femur non-unions: a case series
}

\author{
Giovanni Vicenti ${ }^{1}$, Giuseppe Solarino ${ }^{1}$, Davide Bizzoca ${ }^{1,2^{*}} \mathbb{D}$, Filippo Simone ${ }^{1}$, Giuseppe Maccagnano ${ }^{3}$, \\ Giacomo Zavattini ${ }^{1}$, Guglielmo Ottaviani ${ }^{1}$, Massimiliano Carrozzo ${ }^{1}$, Claudio Buono ${ }^{1}$, Domenico Zaccari ${ }^{1}$ and \\ Biagio Moretti ${ }^{1}$
}

\begin{abstract}
Background: Intertrochanteric and subtrochanteric non-union are rare but challenging complications. In the present study, we investigate the use of a $95^{\circ}$ blade, in association with biological and mechanical augmentation, in the management of intertrochanteric and subtrochanteric femoral non-unions.

Methods: Between October 2015 and February 2021, a retrospective cohort study was conducted at our institution to investigate the use of a $95^{\circ}$ blade, in association with biological and mechanical augmentation, in the management of intertrochanteric and subtrochanteric femoral non-unions, following the mechanical failure of the first device. All the patients underwent a clinical and radiographic follow-up at 6 weeks, 3, 6, 9, 12 and 18 months; at each followup, a plain radiograph of the femur was performed and patients were assessed using Harris Hip Score (HHS) and the Short Form-12 (SF-12) questionnaire.

Results: From October 2015 and February 2021, 40 proximal femur non-unions were managed at our Institution. Fifteen patients out of forty (37.5\%) met the inclusion criteria. The main data of the study are summarized in Table 1; patients' mean was 57 years old (range 19-83); 10 males and 5 females were included in the study. All the patients completely healed clinically and radiologically at an average of 6.1 months (range 4-13). All these patients returned to their pre-injury mobility status. During an average follow-up period of 25 months (range 8-60), the observed complications included wound dehiscence, which was treated with a superficial surgical debridement, a below-the-knee deep vein thrombosis, and a blade plate failure 3 months after the first revision surgery.
\end{abstract}

Conclusions: This study shows the treatment of inter-and sub-trochanteric non-unions with a $95^{\circ}$ blade plate, medial strut allograft, and bone autograft obtained with RIA system, together with a varus malalignment correction, leads to a high percentage of bone healing, with a low incidence of complications and good clinical outcome.

Keywords: femoral non-unions, biologic augmentation, mechanical augmentation, proximal femur fractures, subtrochanteric fractures, osteoporosis, bone fragility, reaming irrigation aspiration (ria)

*Correspondence: da.bizzoca@gmail.com

${ }^{2}$ University of Bari "Aldo Moro, PhD course in Public Health, Clinical Medicine, and Oncology, Piazza Giulio Cesare 11, 70100 Bari, Italy Full list of author information is available at the end of the article

\section{Introduction}

Hip fractures are the most treated fractures around the world [1]. Out of these, intertrochanteric fractures account for almost $50 \%$ of these injuries, while original author(s) and the source, provide a link to the Creative Commons licence, and indicate if changes were made. The images or other third party material in this article are included in the article's Creative Commons licence, unless indicated otherwise in a credit line to the material. If material is not included in the article's Creative Commons licence and your intended use is not permitted by statutory regulation or exceeds the permitted use, you will need to obtain permission directly from the copyright holder. To view a copy of this licence, visit http://creativecommons.org/licenses/by/4.0/. The Creative Commons Public Domain Dedication waiver (http://creativeco mmons.org/publicdomain/zero/1.0/) applies to the data made available in this article, unless otherwise stated in a credit line to the data. 
subtrochanteric fractures account for approximately 7 to $34 \%$ and have a bimodal distribution [2-6]. If young patients are generally involved in high-energy traumatic events (e.g. motor vehicle collisions), elderly patients usually undergo low-energy traumas [7].

Additionally, in the last recent years, a relevant increase in the incidence of subtrochanteric fractures has been detected, partially due to the use of bisphosphonates, especially alendronate, which could promote the genesis of atypical proximal femoral fractures, by weakening the femur lateral cortex [8]. The subtrochanteric area has peculiar features since, from an anatomic point of view, it is an area with a cortical bone predominance, linked to a very poor vascularization, which may cause a difficult and delayed bone healing process after a fracture [9]. Moreover, the peak stress in this segment could reach $57 \mathrm{kPa}$, i.e. the highest value in the entire human skeleton; moreover, compression forces are prevalent on the medial side, whereas shear forces prevail on the lateral side [10-13]. This biomechanical aspect leads to many relevant problems, such as implant fatigue and fixation failure, if the fracture does not promptly heal. Besides that, the anatomical features of the subtrochanteric region, with the deforming strain of abduction from the gluteus medius, flexion and external rotation from the iliopsoas, adduction and shortening of the shaft from the hamstrings and adductors, as well as the degree of comminution of the medial cortical buttress at the level of the fracture constitute a surgical challenge for the orthopaedic surgeon [14]. Thus, the incidence of non-unions or delayed unions in these fractures varies from 7 to $20 \%$ [15-17].

On the other hand, trochanteric fractures, thanks to a better bone vascularization of this anatomical region and the smaller deforming moments here acting, are considerably less frequently involved in the above-mentioned complications. However, in selected cases, including fractures with posteromedial wall comminution, severe osteoporotic bone, inaccurate fracture reduction and poor endomedullary nail implantation, a non-union incidence of $1-2 \%$ is reported [18-21].

In the treatment of intertrochanteric femoral fractures, two different surgical implants are commonly used: intramedullary nail (long Recon or straight) and extramedullary devices. Intramedullary fixation devices are favoured over the extra-medullary fixation, due to the shorter lever arm, the less bending movement across the fracture site and a better load sharing through the implant [22-26]. For all these reasons, the intramedullary nail fixation rate for trochanteric fractures rose from 3 to $67 \%$ over the last two decades. However, the use of this device has relatively stopped the incidence of non-union or delayed union in the subtrochanteric region, which varies from 7 to $20 \%$ [16]. The main reason for non-union in intramedullary fixation is the soft tissue interposing, a complication that requires the fracture open reduction [27]. The management of such a kind of injury has always represented a dilemma for orthopaedic surgeons during the last decades. The main variables that could influence the surgical treatment include bone quality, patient's age and hip osteoarthritis; in presence of good bone stock and young age, reintervention with internal fixation is the treatment of choice [9]. It could be performed with a great variety of implants, such as $95^{\circ}-130^{\circ}$ angled blade plates, with or without the valgus intertrochanteric osteotomy (VITO) or hip screw and side plate (SHS), with or without bone grafting and cementation, to regain the limb's length and rotation [28].

In the present study, we investigate the use of a $95^{\circ}$ blade, in association with biological and mechanical augmentation, in the management of intertrochanteric and subtrochanteric femoral non-unions.

\section{Methods}

Between October 2015 and February 2021, a retrospective cohort study was conducted at our institution to investigate the use of a $95^{\circ}$ blade, in association with biological and mechanical augmentation, in the management of intertrochanteric and subtrochanteric femoral non-unions, following the mechanical failure of the first device. Ethical clearance was obtained from the Local Ethical Committee (Prot. n. 5556/2018), as per the 1964 Declaration of Helsinki, and all the patients gave informed consent before enrollment in the study.

Revision surgical procedure was performed by the same orthopaedic surgeon at the Traumatology Department of our Hospital. Non-union was defined as the absence of radiographic healing progression 6 months after surgery, or hardware failure at more than 5 months after surgery. All the atrophic aseptic inter- and subtrochanteric non-unions with mechanical failure presented to our institution were included in this study. The exclusion criteria were hypertrophic non-unions, pathologic fractures, signs and symptoms of infection (i.e., increased CRP or ESR), and subtrochanteric atypical fractures. This was a monocentric, single-surgeon study.

The following data were collected: patients' demographics, initial fracture pattern, first surgical procedure, time from primary surgery to reintervention, revision surgery complications and time to final union. Plain radiographs of the pelvis, hip and femur, and a CT scan of the affected femur were performed in all the patients before the surgical revision procedure.

The surgical procedures were performed by the same surgical and anesthesiology team, under spinal anaesthesia. After positioning the patient supine on a traction table, the Reaming Irrigation Aspiration (RIA) 
system (De Puy Synthes, Raynham, Massachusetts, USA) was used in the contralateral femur to obtain the bone autograft. The broken intramedullary device was then removed from the non-union site, using a universal extraction system. In three cases out of 15 , this extractor could not be used, therefore the "two k-wires technique" (Fig. 1) was used to remove the nail. Then soft tissue debridement and non-union site cruentation were performed. Deep samples were also taken sent to exclude the presence of a septic non-union. The patients were then treated with a $95^{\circ}$ blade plate (DePuy Synthes), a medial femoral strut allograft, and the bone autograft taken from the contralateral femur. The fractures were reduced with the use of a screw jack to give compression and decrease the varus malalignment. In 6 patients, with an oblique fracture line, a lag screw was used. In 2 cases used Bioactive glass (FIBERGRAFT ${ }^{\circledR}$, DePuy Synthes, North America Inc., West Chester, PA, USA). In no case, we have performed a valgus osteotomy (VITO or VSTO). Finally, the bone autograft was implanted at the debrided nonunion site and a layered suture was performed.

The postoperative protocol included partial weight bearing using two crutches for 4-6weeks, followed by a progressive increase to full weight-bearing to the patient's tolerance. Thromboprophylaxis with Low Molecular Weight Heparin (LMWH) was administered for 4-6weeks. All the patients underwent a clinical and radiographic follow-up at 6 weeks, 3, 6, 9, 12 and
18 months; at each follow-up, a plain radiograph of the femur was performed and patients were assessed using Harris Hip Score (HHS) and the Short Form-12 (SF-12) questionnaire.

\section{Results}

From October 2015 and February 2021, 40 proximal femur non-unions were managed at our Institution. Fifteen patients out of forty (37.5\%) met the inclusion criteria; the reaming patients were excluded for the following reasons: lost to follow-up $(n=5)$; subtrochanteric atypical fractures $(n=17)$; infected non-union $(n=3)$.

The main data of the study are summarized in Table 1; patients' mean age was 57 years old (range 19-83); 10 males and 5 females were included in the study.

All the primary surgical procedures failed because of mechanical problems: in 10 out of 14 IMN cases, the nail broke in the metaphyseal part, as described by Giannoudis et al. [9]. This is a critical area, where the forces are transmitted from the femoral neck to the diaphysis, and the cross-sectional area of the nail is reduced by approximately $70 \%$. The average time from the first surgery to the device failure was 5 months (range 3-9 months). In the remaining 4 cases, the nail was intact, but the fracture non-union was evident. In the only non-union case managed with an SHS, this device broke just above the first cortical screw. In all the cases, the non-union was maligned in varus.

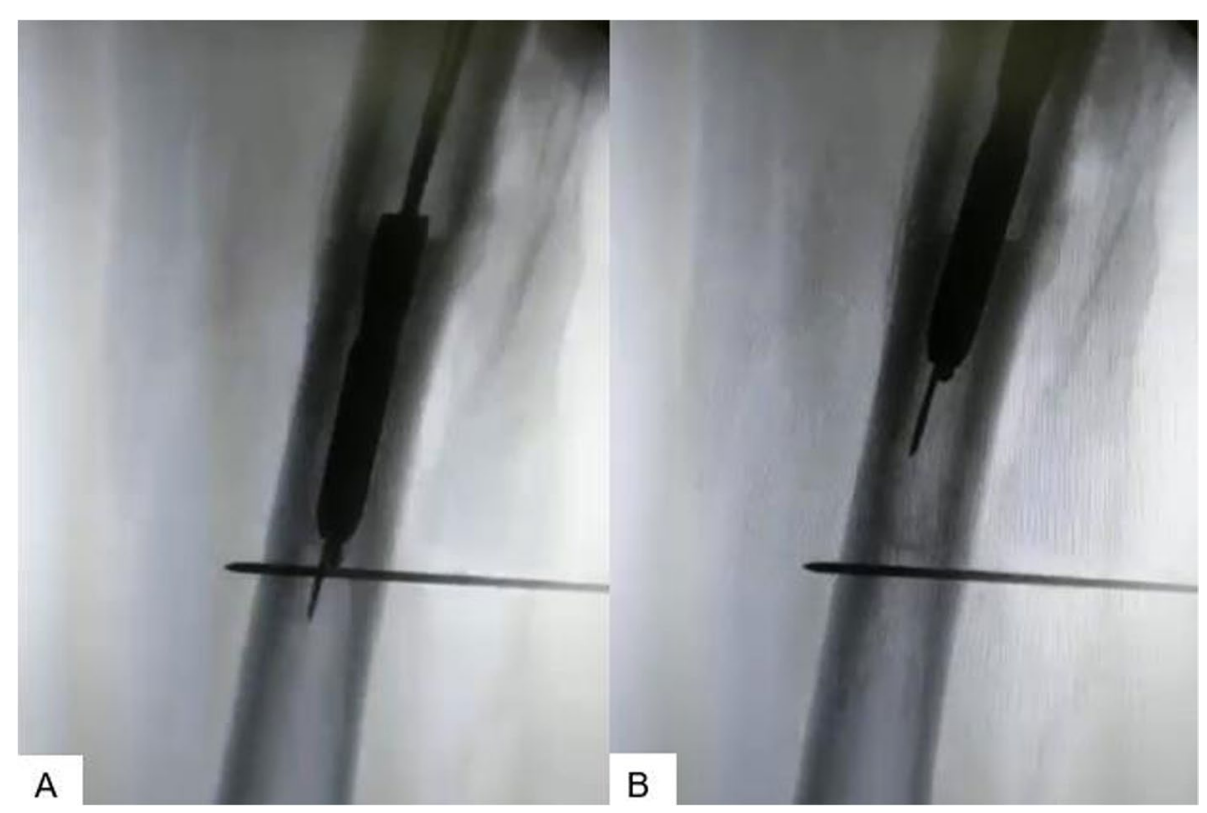

Fig. 1 (a-b)- "2 k wires extracting technique". A smart technique in all the cases in which the extractor cannot be used. A k wire is straight, and it is used to add width only, while the other one has got a curve ending to pass through the nail easily but pulling it out the opposite way. The perpendicular K wire avoids the distal migration of the nail 
Table 1 Main data of the study

\begin{tabular}{lllllll}
\hline Pt & Age/gender & Type of trauma & Fracture classification & $\begin{array}{l}\text { Time to failure } \\
\text { (months) }\end{array}$ & $\begin{array}{l}\text { Union } \\
\text { (months) }\end{array}$ & Complications \\
\hline 1 & 19/male & High & Subtrochanteric & 5 & 7 & N/A \\
2 & $54 /$ male & High & Subtrochanteric & 4 & 5 & Wound dehiscence \\
3 & $72 /$ male & Low & Subtrochanteric & 7 & 7 & N/A \\
4 & 22/Female & High & Subtrochanteric & 6 & 4 & N/A \\
5 & $55 /$ male & High & Subtrochanteric & 5 & 4 & N/A \\
6 & 83/female & Low & Intertrochanteric & 3 & 8 & Below knee deep vein thrombosis \\
7 & $41 /$ male & High & Subtrochanteric & 9 & 13 & Breakage of blade plate-second \\
& & & revision to double plate construct \\
8 & 63/female & Low & Intertrochanteric & 7 & 6 & N/A \\
9 & 49/male & High & Subtrochanteric & 5 & 4 & N/A \\
10 & 58/female & High & Intertrochanteric & 5 & 5 & N/A \\
11 & 74/male & Low & Intertrochanteric & 6 & 7 & N/A \\
12 & 68/male & high & Subtrochanteric & 5 & 3 & N/A \\
13 & $70 /$ female & Low & Subtrochanteric & 6 & 7 & N/A \\
14 & $58 /$ male & High & Subtrochanteric & 4 & 5 & N/A \\
15 & 64/male & High & Subtrochanteric & 5 & 7 & N/A \\
\hline
\end{tabular}

All the patients completely healed clinically and radiologically at an average of 6.1 months (range 4-13) (Figs. 2 and 3). All these patients returned to their pre-injury mobility status. During an average follow-up period of 25 months (range 8-60), the observed complications included wound dehiscence, treated with a superficial surgical debridement, a below-the-knee deep vein thrombosis, and a blade plate failure 3 months after the first revision surgery. This case had second revision surgery with a double-plate construct $\left(95^{\circ}\right.$ blade plate and an anterior femoral plate), with a medial femoral strut allograft and RIA graft. The bone union was reached after 7 months (Fig. 4).

The mean HHS gradually increased in all the patients, starting from 50.1 (at 3 months follow-up), reaching 72.3 at 6 months follow-up, 76.5 at 9 months, 82.4 at 12 months and getting finally to 86.7 to the last control (18 months).

The SF-12 score, on the contrary, increased slowly during the first months, due to the residual pain of the surgery and the initial limitations to the movement, but at the end reached a high peak, just as the HHS score. The mean scores were: 45.4 at 3 months, 55.6 at 6 months, 69.4 at 9 months, 78.4 at 12 months, ending with 85.3 at the 18th-month follow-up.

\section{Discussions}

Mechanical failure of trochanteric and subtrochanteric fractures is an emerging complication due to the increasing prevalence of proximal femur fragility fractures $[2,3]$. Trochanteric and subtrochanteric non-unions are caused by several factors, including both surgeon's related (i.e., poor surgical technique; implant choice; fracture site exploration; lack of a post-operative osteoporotic therapy) and patients related factors (i.e., comorbidities, postoperative complications liable to delate the rehabilitation timing; severe osteoporosis).

The treatment of a trochanteric and subtrochanteric non-union is a highly challenging endeavour for orthopaedic surgeons and requires a sound healing and rehabilitative process. The implant choice plays a central role in the management of such a complex injury. Currently, 289 cases of inter- and sub-trochanteric non-unions have been described in the literature by 11 different authors (Table 2). 190 cases out of 289 (65.7\%) were treated with a blade plate and the $95^{\circ}$ blade plate was employed in 117 cases out of 190 cases (61.57\%). Thus, this device is the most used in revision surgery for inter- and sub-trochanteric non-unions.

In the present study, the treatment of 15 proximal femur non-unions (mean age: 57 years old; male:10, female:5) managed with a 95-degree angled blade plate, in association with biological and mechanical augmentation. All the patients included in the present study completely healed clinically and radiologically at an average of 6.1 months (range 4-13). All these patients returned to their pre-injury mobility status. During an average follow-up period of 25 months (range 8-60), the observed complications included wound dehiscence, which was treated with a superficial surgical debridement, a belowthe-knee deep vein thrombosis, and a blade plate failure 3 months after the first revision surgery. The findings of 


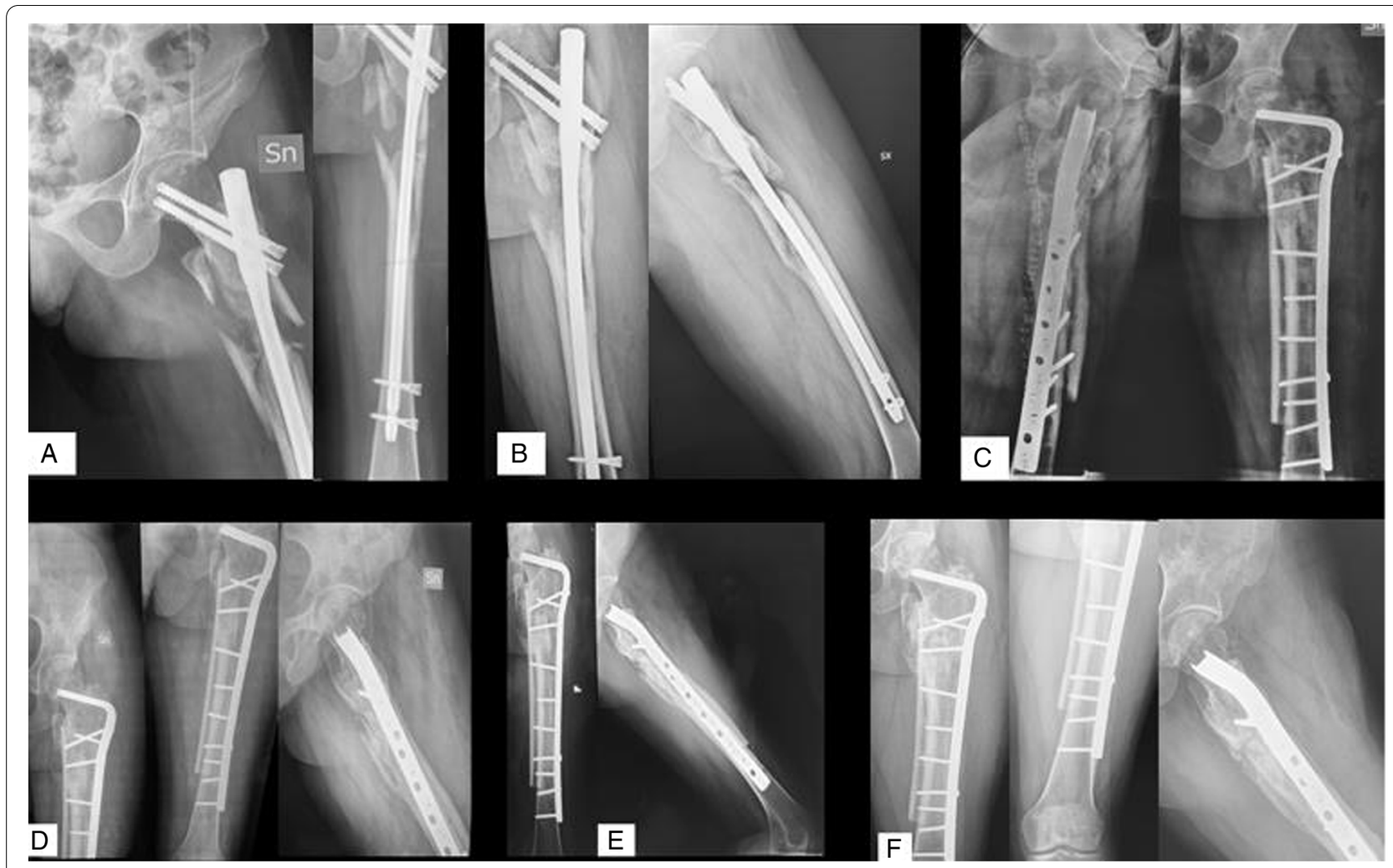

Fig. 2 A AP and LL radiograph of femur subtrochanteric fracture of a 22 years old girl, due to a high energy trauma; $\mathbf{B}$ AP and LL radiographs at 6 months follow-up, showing a hypertrophic non-union; C AP and LL of the reintervention with blade plate, medial strut allograft and blade plate failure after 3 months; D AP and LL radiograph of postoperative at 2 months follow-up; $\mathbf{E}$ AP and LL radiograph at 4 months follow-up; $f$ ) AP and LL radiograph at 9 months follow-up

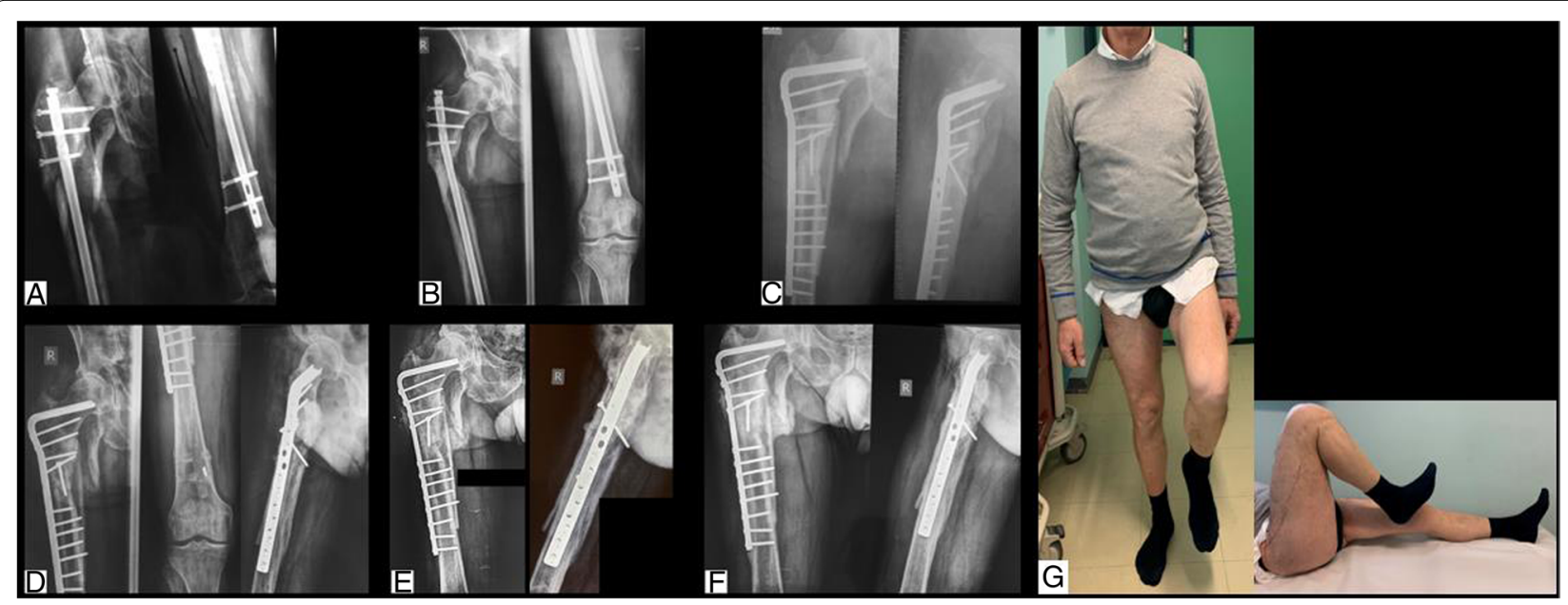

Fig. 3 A radiograph of femur subtrochanteric fracture of a 55 years old man, following a high-energy trauma; $\mathbf{B}$ radiographs of the non-union with a broken EM nail, at 5 months post-op; C AP and LL radiographs of the reintervention with $95^{\circ}$ blade plate, medial strut allograft, RIA system and lag screw; D AP and LL radiographs at 2 months follow-up; E AP and LL radiograph at 4 months follow-up; F AP and LL radiograph at 9 months follow-up; G clinical evaluation of the patient at 9 months follow-up 


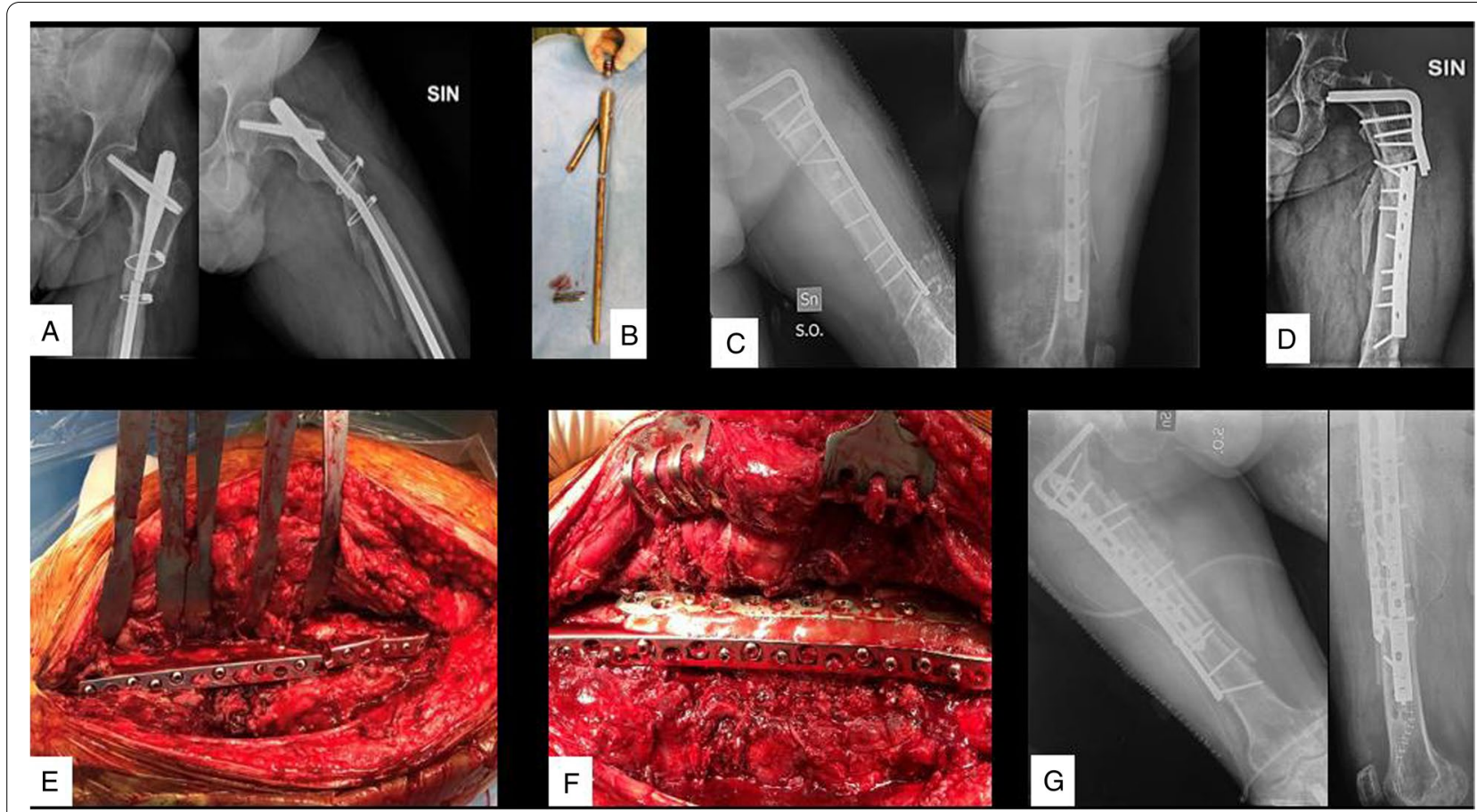

Fig. 4 A AP and LL radiographs of the femur, showing a subtrochanteric non-union with a broken EM nail, at 1 year after the primary surgery; B intra-operative image of the broken EM nail; C AP and LL radiographs of the first reintervention with $95^{\circ}$ blade plate, medial strut allograft and RIA autograft; $\mathbf{D}$ blade plate failure, at 3 months follow-up; $\mathbf{E}$ intraoperative image of the broken blade plate; $\mathbf{F}$ intraoperative image with the double-plating revision technique and medial strut allograft; $\mathbf{G}$ AP and LL radiographs of the second reintervention

the present study show the 95-degree angled plates are a valid device in the management of proximal femur non-unions.

$\mathrm{Wu}$ et al. reported an exchange nailing to treat aseptic non-unions of the trochanteric region with excellent results, recommending an over-reaming of $1 \mathrm{~mm}$ or more [38]. Charnley and Ward [39] successfully treated two non-unions with a reconstruction nail and suggested its use, especially in the elderly, since it may allow an earlier full weight-bearing, compared to a blade plate. Haidukewych and Berry published the results of the treatment of 23 subtrochanteric non-unions with both intra- and extramedullary implants (15 versus 8 , respectively) [33]. In 20 patients out of 21 patients available for follow-up, the union was reached. Barquet et al. reported the results of the treatment of 29 patients with a non-infected subtrochanteric non-union with a long gamma nail [34]. In two patients, hardware failure necessitated re-intervention with a long gamma nail to reach union. Finally, 25 of the 26 non-unions healed.

All these papers clearly show that intramedullary reintervention is a suitable treatment for these fractures. The only contraindication for its use is a malalignment associated with a leak of compression on the bone fragments, both problems that can be barely corrected by a second nail; in this case, the blade plate represents a good compromise.

The varus malalignment is a well-recognized risk factor for failure and non-union of these fractures [31], which usually works together with an increased bending stress at the medial femoral cortex and comminution of the medial buttress [40]. For all these reasons, treating varus malalignment represent the priority in a reintervention, and a valgus intertrochanteric osteotomy (VITO) could represent a valid solution. As reported by Muller et al., this technique is used in case of a head shaft angle (HAS) $\leq 90^{\circ}$, followed by a $110^{\circ} / 120^{\circ}$ angled blade plate to restore the anatomy and length of the limb. In a recent work published by Bhowmich et al. [18], it is proposed an algorithm for decision making in the management of these injuries based on fracture pattern, anatomy, the status of the bone union and quality of the bone.

Many papers in the last decades have shown great results with the blade plate reintervention, both in intertrochanteric and subtrochanteric revisions (Table 1). Haidukewych et al. [29] reported the results of 11 intertrochanteric non-unions managed with blade plate and autograft. These authors observed $\mathrm{r}$ a bone union rate of 95\%; none of the patients showed femoral head avascular necrosis at 27 months follow-up [29]. Said et al. [30] 


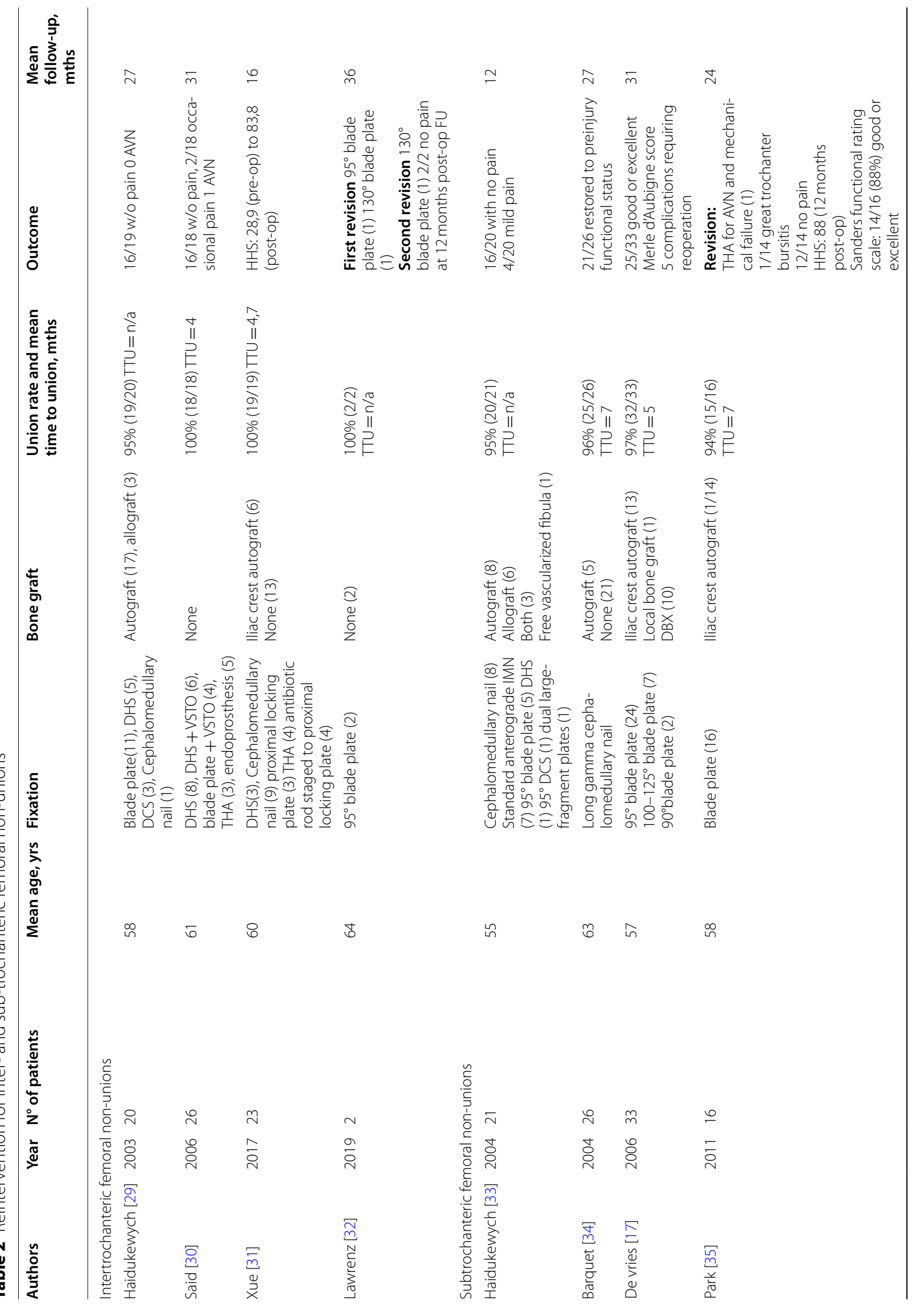




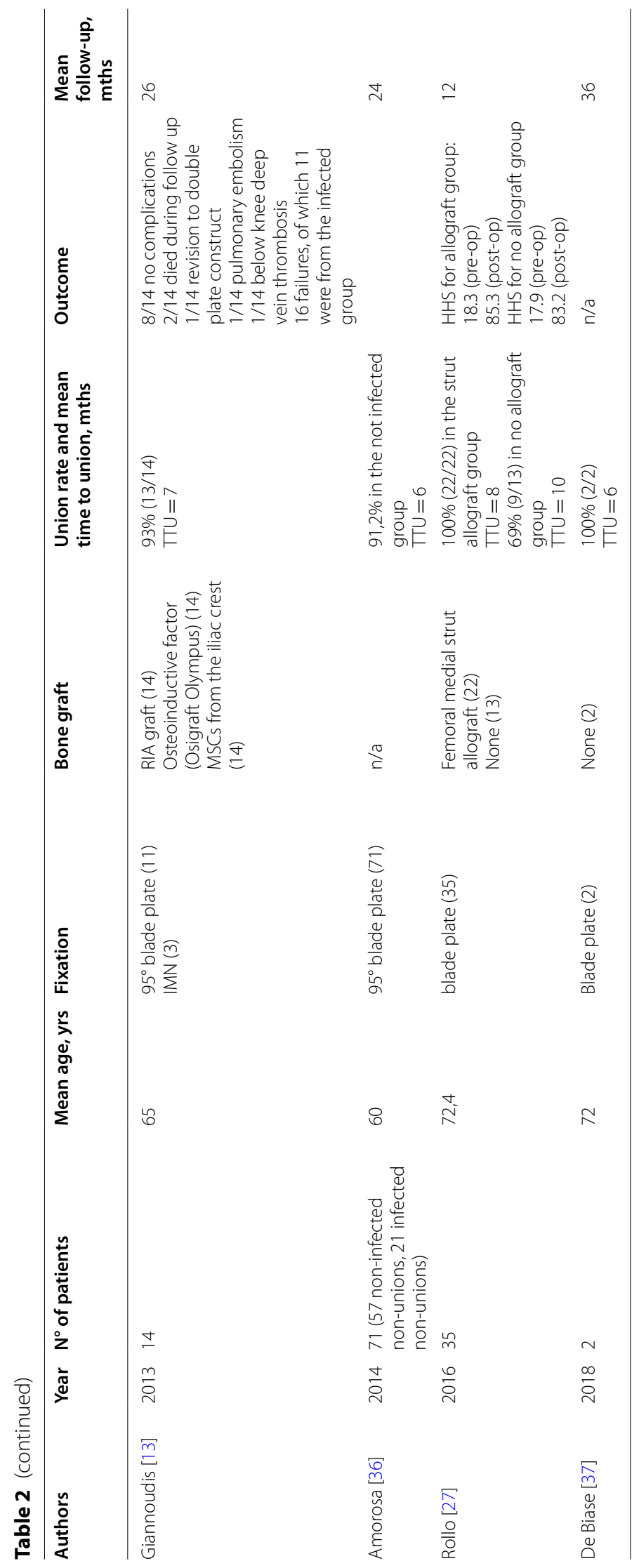


treated 4 subtrochanteric non-unions with blade plate and valgus subtrochanteric osteotomy (VSTO) and no bone graft, reaching $100 \%$ of bone union at a mean time of 4 months. Lawrenz et al. [32] performed blade plate reintervention on 2 patients, both followed by a revision with a $95^{\circ}$ blade plate and a $130^{\circ}$ blade plate, the latter together with a VITO. The first one, on the contrary, had a second revision with a $130^{\circ}$ blade plate and VITO, within a few months after surgery, because of a mechanical failure. Both patients presented no pain at a 36-month follow-up. Haidukewych et al. [33] described the treatment of 5 patients with a $95^{\circ}$ blade plate, together with an autograft, reporting bone union in all the patients, and residual mild pain in just one out of 5 at 12 months follow-up. De Vries et al. [17] treated 33 patients with subtrochanteric non-union with a $95^{\circ}$ blade plate in 24 cases, a $125^{\circ}$ blade plate in 7 cases and a $90^{\circ}$ blade plate in 2 cases. In 13 cases these authors used an iliac crest autograft, a DBX Putty in 10 cases, and one case a local bone graft. The bone union was $97 \%$ at a mean followup of 5 months, with good or excellent results at Merle d'Aubigne score at a 31-month follow-up.

Park et al. [35] described treatment with blade plate for 16 subtrochanteric non-union, in one case together with an iliac crest autograft. Bone union was reached in $94 \%$ of patients at a mean time of 7 months. In one case, there was a mechanical failure with AVN that required a THA, while in another case there was great trochanter bursitis. HHS score was 88 at a 24-month postoperative follow-up, and Sanders functional rating scale was good or excellent in $88 \%$ of patients.

Giannoudis et al. [9] treated 11 patients with subtrochanteric non-union with a $95^{\circ}$ blade plate, together with contralateral RIA ${ }^{\circledR}$ graft, osteoinductive factors (Osigraft ${ }^{\circledR}$ Olympus) and MSCs from the iliac crest, pursuing the so-called "Diamond concept". In 13 cases out of 14 (93\%), there was a bone union at a mean time of 7 months, although in a case it was necessary a revision to a double plate construct.

Rollo et al. [27] treated 35 subtrochanteric nonunions with a blade plate, in 22 cases together with a femoral medial strut allograft, while in the remaining 13 cases no allograft was used. In the first group, the bone union was reached in all cases at a mean time of 8 months, while in the second group 4 patients had a mechanical failure, which required a reintervention with a double plate construct. The mean time of bone union was 8 months in the first group and 10 months in the second group. HHS score improved in the first group from 18.3 (pre-op) to 85.3 (12 months post$\mathrm{op}$ ), while in the second group from 17.9 (pre-op) to 83.2 (12 months post-op). De Biase et al. [37] reported the treatment of 2 patients with subtrochanteric non-unions treated with blade plate. Both the patients reached bone union at a mean time of 6 months. Amorosa et al. [36] described the use of a $95^{\circ}$ blade plate to 71 patients with subtrochanteric or distal femur nonunion. The overall rate of healing was $77.5 \%$, but more specifically was $91.2 \%$ for non-infected non-unions and $47.6 \%$ for infected non-unions. They concluded this device is a very effective reduction aid for the aseptic non-unions of the proximal and distal femur with acceptable healing rates.

In the last few years, a great debate has been reserved for bone grafting in trochanteric revision surgery. In a recent article by Mardani-Kivi et al. [41], 41 patients with subtrochanteric non-unions were treated with autogenous bridging bone grafting (corticocancellous bone harvested from the iliac crest) and double-plate fixation. An infected non-union was observed in 8 patients out of 41 [37]. The full union was obtained even in the infected cases, with only a case of deep vein thrombosis and a case of pulmonary embolism. In a similar study, Odeh et al. [42] reported the outcomes of rigid internal fixation with autogenous bone grafting (free non-vascularized half fibula) in the treatment of femoral shaft non-union of 21 patients. The full clinical and radiological union was seen in all the patients. On the contrary, in a work made by Won et al. [43], there was no difference in the bone union between a group of subtrochanteric non-unions treated with re-nailing with bone grafting and the other one treated without bone grafting. They conclude the outcome of subtrochanteric revision surgery are mainly influenced by fracture type (atypical/typical), the number of previous surgeries and the presence of varus and sagittal anterior angulation [41].

Additionally, iliac and fibular autologous bone grafting is associated with significant donor site morbidity and can result in limited graft availability [44]. Moreover, in the elderly population osteopenia and red to yellow bone marrow replacement precludes the harvesting of graft from the iliac crest. In these cases, the RIA system from the contralateral femur (as we previously described in our experience $[20,45]$ ) represents a wise choice, together with the use of growth factors and scaffolds. This was known as the triangular concept, afterwards modified by Giannoudis et al. [9] into the "Diamond concept", with the addition of mechanical stability to these three dimensions of biological enhancement of bone healing, highlighting the fundamental role of stability in these fractures.

The strengths of our study include the use of a single type of implant and the single-stage surgical procedure, performed by the same surgeon. The weaknesses of our study include its retrospective design, the lack of a control group and the relatively small sample size. 


\section{Conclusions}

This study shows that the treatment of inter- and sub-trochanteric non-unions with a $95^{\circ}$ blade plate, medial strut allograft, and bone autograft obtained with RIA system, together with a varus malalignment correction, leads to a high percentage of bone union, with a low incidence of complications and good clinical outcome.

\section{Abbreviations}

HHS: Harris Hip Score; SF-12: Short-Form 12; RIA: Reamer Irrigator Aspirator; CRP: C- Reactive Protein; ESR: Erythrocyte Sedimentation Rate; VITO: Valgus Intertrochanteric Osteotomy; VSTO: Valgus Subtrochanteric Osteotomy; LMWH: Low Molecular Weight Heparin.

\section{Acknowledgements}

None.

\section{About this supplement}

This article has been published as part of BMC Musculoskeletal Disorders Volume 22 Supplement 2 2021: All about the hip. The full contents of the supplement are available at https://bmcmusculoskeletdisord.biomedcentral.com/ articles/supplements/volume-22-supplement-2.

\section{Authors' contributions}

S.F., S. G., M.G., Z.G., O.G., C.M., B.C and Z.D. drafted the manuscript and performed data acquisition; V. G., B. D. and M. B. made substantial contributions to the conception of the work, to the interpretation of data and revised the work critically for important intellectual content. All authors read and approved the final manuscript.

\section{Funding}

None.

\section{Availability of data and materials}

The datasets used and/or analyzed during the current study are available from the corresponding author on reasonable request.

\section{Declarations}

\section{Ethics approval and consent to participate}

Ethical clearance was obtained from our centre's clinical research ethics, as per the 1964 Declaration of Helsinki (Prot. n. 5556/2018).

All patients gave written informed consent before enrolment in the study.

\section{Consent for publication}

All patients gave written consent to publication before enrolment in the study.

\section{Competing interests}

All authors declare no support from any organization for the submitted work; no financial relationships with any organizations that might have an interest in the submitted work in the previous three years; and no other relationships or activities that could appear to have influenced the submitted work.

\section{Author details}

${ }^{1}$ Department of Basic Medical Sciences, Neuroscience and Sense Organs, School of Medicine, University of Bari "Aldo Moro", AOU Consorziale Policlinico, Orthopaedic \& Trauma Unit, Bari, Italy. ${ }^{2}$ University of Bari "Aldo Moro, PhD course in Public Health, Clinical Medicine, and Oncology, Piazza Giulio Cesare 11, 70100 Bari, Italy. ${ }^{3}$ Riuniti Hospital, Foggia, Italy.

Received: 11 December 2021 Accepted: 3 February 2022

Published online: 28 February 2022

\section{References}

1. Gromov K, Fristed JV, Brix M, Troelsen A. Completeness and data validity for the Danish Fracture Database. Dan Med J. 2013:60:A4712.

2. Parker MJ, Dutta BK, Sivaji C, Pryor GA. Subtrochanteric fractures of the femur. Injury. 1997;28:91-5.

3. Bhandari M, Schemitsch E, Jönsson A, Zlowodzki M, Haidukewych GJ. Gamma nails revisited: Gamma nails versus compression hip screws in the management of intertrochanteric fractures of the hip: A meta-analysis. J Orthop Trauma. 2009:23(6):460-4.

4. Vicenti G, Bizzoca D, Pascarella R, Delprete F, Chiodini F, Daghino W, et al. Development of the Italian fractures registry (RIFra): A call for action to improve quality and safety. Injury. 2020;S0020-1383(20):30852-4.

5. Vicenti G, Bizzoca D, Caruso I, Nappi VS, Giancaspro G, Carrozzo M, et al. New insights into the treatment of non-healing diabetic foot ulcers. J Biol Regul Homeost Agents. 2018;32(6 Suppl. 1):15-21 http://www.ncbi.nlm. nih.gov/pubmed/30644276. Accessed 28 Jan 2019.

6. Piazzolla A, Bizzoca D, Solarino G, Moretti L, Moretti B. Vertebral fragility fractures: clinical and radiological results of augmentation and fixationa systematic review of randomized controlled clinical trials. Aging Clin Exp Res. 2020;32:1219-32.

7. Nieves JW, Bilezikian JP, Lane JM, Einhorn TA, Wang Y, Steinbuch M, et al. Fragility fractures of the hip and femur: Incidence and patient characteristics. Osteoporos Int. 2010;21:399-408.

8. Black DM, Abrahamsen B, Bouxsein ML, Einhorn T, Napoli N. Atypical femur fractures: Review of epidemiology, relationship to bisphosphonates, prevention, and clinical management. Endocr Rev. 2019;40:333-68.

9. Giannoudis PV, Ahmad MA, Mineo GV, Tosounidis TI, Calori GM, Kanakaris NK. Subtrochanteric fracture non-unions with implant failure managed with the "diamond" concept. Injury. 2013;44(SUPPL.1):S76-81.

10. Tencer AF, Johnson KD, Johnston DWC, Gill K. A biomechanical comparison of various methods of stabilization of subtrochanteric fractures of the femur. J Orthop Res. 1984;2:297-305.

11. Vicenti G, Pesce V, Tartaglia N, Abate A, Mori CM, Moretti B. Micromotion in the fracture healing of closed distal metaphyseal tibial fractures: A multicentre prospective study. Injury. 2014;45(Suppl 6):S27-35. https:// doi.org/10.1016/j.injury.2014.10.019.

12. Carrozzo M, Vicenti G, Pesce V, Solarino G, Rifino F, Spinarelli A, et al. Beyond the pillars of the ankle: A prospective randomized CT analysis of syndesmosis' injuries in Weber B and C type fractures. Injury. 2018;49:S5460. https://doi.org/10.1016/j.injury.2018.10.005.

13. Vicenti G, Bizzoca D, Carrozzo M, Nappi V, Rifino F, Solarino G, et al. The ideal timing for nail dynamization in femoral shaft delayed union and non-union. Int Orthop. 2019;43:217-22. https://doi.org/10.1007/ s00264-018-4129-y.

14. Kuzyk PRT, Bhandari M, McKee MD, Russell TA, Schemitsch EH. Intramedullary versus extramedullary fixation for subtrochanteric femur fractures. J Orthop Trauma. 2009:23:465-70.

15. Sims SH. Subtrochanteric femoral fractures. Orthop Clin N Am. 2002:33:113-26.

16. Craig NJA, Maffulli N. Subtrochanteric fractures: Current management options. Disabil Rehabil. 2005;27:1181-90.

17. De Vries JS, Kloen P, Borens O, Marti RK, Helfet DL. Treatment of subtrochanteric non-unions. Injury. 2006:37:203-11.

18. Bhowmick K, Matthai T, Boopalan PRJ, Jepegnanam TS. Decision making in the management of malunion and non-union of intertrochanteric fractures of the hip. HIP Int. 2020;30:793-8.

19. Ciaffa V, Vicenti G, Mori CM, Panella A, Conserva V, Corina G, et al. Unlocked versus dynamic and static distal locked femoral nails in stable and unstable intertrochanteric fractures. A prospective study. Injury. 2018;49:S19-25. https://doi.org/10.1016/j.injury.2018.09.063.

20. Demitri S, Vicenti G, Carrozzo M, Bizzoca D, De Franceschi D, Moretti B. The Masquelet technique in the treatment of a non-infected open complex fracture of the distal tibia with severe bone and soft tissue loss: A case report. Injury. 2018;49:S58-62.

21. Notarnicola A, Tamma R, Moretti L, Fiore A, Vicenti G, Zallone A, et al. Effects of radial shock waves therapy on osteoblasts activities. Musculoskelet Surg. 2012;96:183-9.

22. Parker MJ, Handoll HH. Gamma and other cephalocondylic intramedullary nails versus extramedullary implants for extracapsular hip fractures in adults. Cochrane Database Syst Rev. 2010;(3):CD000093. 
23. Mori CM, Vicenti G, Carrozzo M, Picca G, Bizzoca D, Leone A, et al. The fake unlocked femoral nail: A configuration to avoid in stable pertrochanteric femur fractures. Injury. 2018;49(Suppl 3):S32-6.

24. Caiaffa V, Vicenti G, Mori C, Panella A, Conserva V, Corina G, et al. Is distal locking with short intramedullary nails necessary in stable pertrochanteric fractures? A prospective, multicentre, randomised study. Injury. 2016;47(Suppl 4):S98-106.

25. Vicenti G, Bizzoca D, Nappi V, Pesce V, Solarino G, Carrozzo M, et al. Serum biomarkers in the diagnosis of periprosthetic joint infection: consolidated evidence and recent developments. Eur Rev Med Pharmacol Sci. 2019:23:43-50.

26. Vicenti G, Pesce V, Bizzoca D, Nappl V, Palmiotto F, Carrozzo M, et al. Perioperative plasmatic presepsin levels in patients undergoing total hip or knee replacement: A preliminary study. J Biol Regul Homeost Agents. 2017;31:1081-5.

27. Rollo G, Tartaglia N, Falzarano G, Pichierri P, Stasi A, Medici A, et al. The challenge of non-union in subtrochanteric fractures with breakage of intramedullary nail: evaluation of outcomes in surgery revision with angled blade plate and allograft bone strut. Eur J Trauma Emerg Surg. 2017;43:853-61.

28. Bartoníček J, Skála-Rosenbaum J, Douša P. Valgus intertrochanteric osteotomy for malunion and non-union of throchanteric fractures. J Orthop Trauma. 2003;17:606-12.

29. Haidukewych GJ, Berry DJ. Salvage of failed internal fixation of intertrochanteric hip fractures. Clin Orthop Relat Res. 2003:412:184-8.

30. Said GZ, Farouk O, El-Sayed A, Said HG. Salvage of failed dynamic hip screw fixation of intertrochanteric fractures. Injury. 2006;37:194-202.

31. Shukla S, Johnston P, Ahmad MA, Wynn-Jones H, Patel AD, Walton NP. Outcome of traumatic subtrochanteric femoral fractures fixed using cephalo-medullary nails. Injury. 2007;38:1286-93.

32. Lawrenz JM, Marshall DC, Patterson BM. The utility of the angled blade plate in hip fracture non-union treatment. OTA Int Open Access J Orthop Trauma. 2019;2:e041.

33. Haidukewych GJ, Berry DJ. Non-union of fractures of the subtrochanteric region of the femur. Clin Orthop Relat Res. 2004;419:185-8.

34. Agarwal A, Agarwal A, Barquet A. The treatment of subtrochanteric nonunions with the long Gamma nail: Twenty-six patients with a minimun 2-year follow-up (multiple letters). J Orthop Trauma. 2005;19:294.

35. Park Y-S, Kim J-H, Woo K-J, Lim S-J. Treatment of Subtrochanteric Nonunion with a Blade Plate. J Korean Orthop Assoc. 2011;46:42.

36. Amorosa LF, Jayaram PR, Wellman DS, Lorich DG, Helfet DL. The use of the 95-degree-angled blade plate in femoral non-union surgery. Eur J Orthop Surg Traumatol. 2014;24:953-60.

37. De Biase P, Biancalani E, Martinelli D, Cambiganu A, Bianco S, Buzzi R. Subtrochanteric fractures: two case reports of non-union treatment. Injury. 2018:49:59-15.

38. Wu CC. Exchange nailing for aseptic non-union of femoral shaft: A retrospective cohort study for effect of reaming size. J Trauma Acute Care Surg. 2007;63:859-65.

39. Charnley GJ, Ward AJ. Reconstruction femoral nailing for non-union of subtrochanteric fracture A revision technique following dynamic condylar screw failure. Int Orthop. 1996;20:55-7.

40. Park J, Yang KH. Correction of malalignment in proximal femoral nailing-reduction technique of displaced proximal fragment. Injury. 2010:41:634-8.

41. Mardani-Kivi M, Karimi Mobarakeh M, Keyhani S, Azari Z. Double-plate fixation together with bridging bone grafting in non-union of femoral supracondylar, subtrochanteric, and shaft fractures is an effective technique. Musculoskelet Surg. 2020;104:215-26.

42. Odeh R, Al-Karmi S, Munzir Odeh WB. Double plating with autogenous bone grafting in the treatment of non-union of femoral shaft fractures. R Med Serv. 2015;22:6-12.

43. Shin WC, Jang JH, Moon NH, Jun SB. Is open bone graft always necessary when treating aseptic subtrochanteric non-union with a reamed intramedullary nail? BMC Musculoskelet Disord. 2021;22:145.

44. Arrington ED, Smith WJ, Chambers HG, Bucknell AL, Davino NA. Complications of iliac crest bone graft harvesting. Clin Orthop Relat Res. 1996:329:300-9

45. Vicenti G, Bizzoca D, Cotugno D, Carrozzo M, Riefoli F, Rifino F, et al. The use of a gentamicin-coated titanium nail, combined with RIA system, in the management of non-unions of open tibial fractures: A single centre prospective study. Injury. 2020;51:S86-91.

\section{Publisher's Note}

Springer Nature remains neutral with regard to jurisdictional claims in published maps and institutional affiliations.
Ready to submit your research? Choose BMC and benefit from:

- fast, convenient online submission

- thorough peer review by experienced researchers in your field

- rapid publication on acceptance

- support for research data, including large and complex data types

- gold Open Access which fosters wider collaboration and increased citations

- maximum visibility for your research: over $100 \mathrm{M}$ website views per year

At BMC, research is always in progress.

Learn more biomedcentral.com/submissions 